\title{
1 Sex in the wild: how and why field-based studies 2 contribute to solving the problem of sex
}

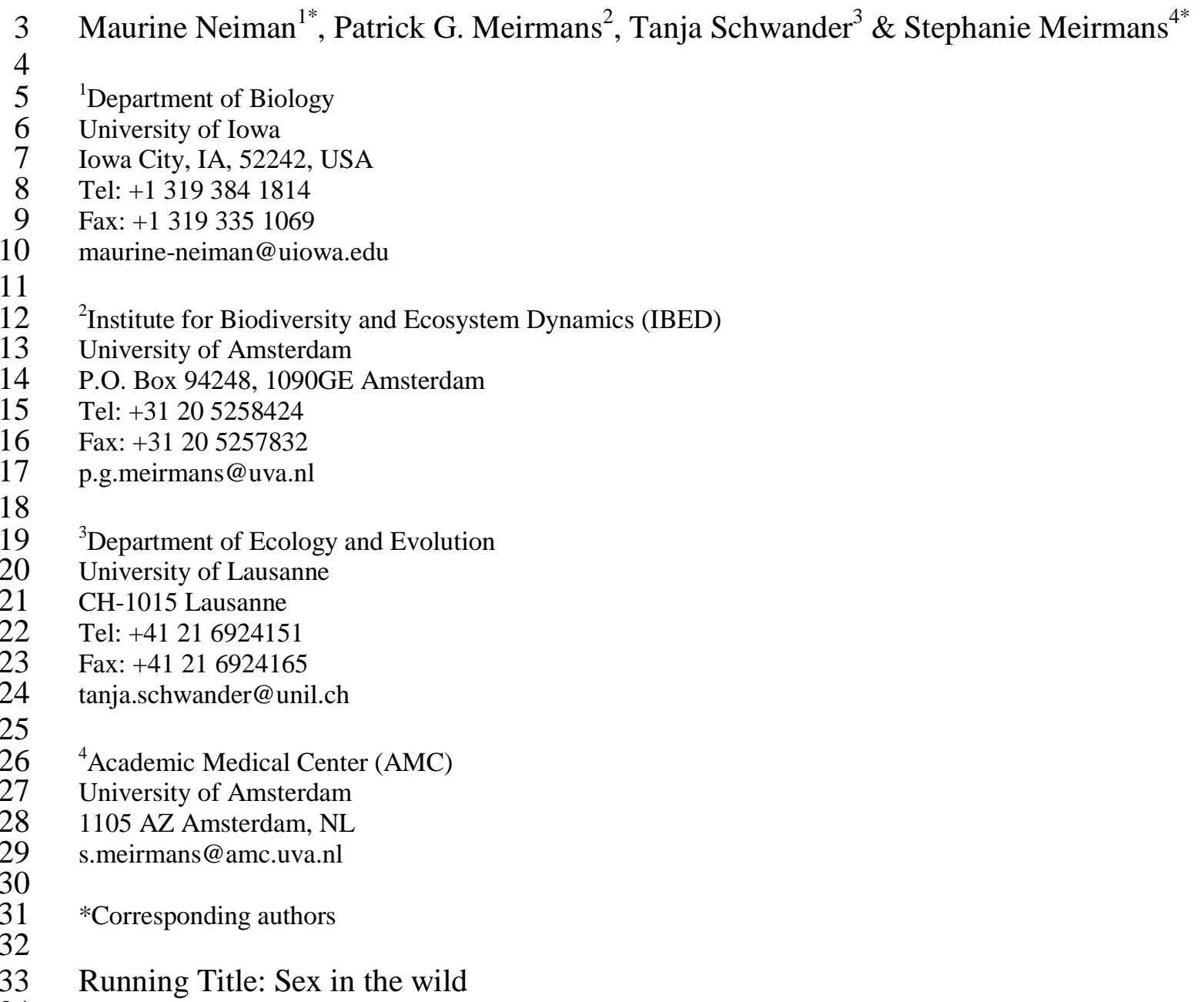

Keywords: sexual reproduction, asexual reproduction, parthenogenesis, Red Queen, niche 36 differentiation, Muller's ratchet

\section{Author contributions}

39 SM and MN conceived the paper idea, SM, PM, MN, and TS designed the review strategy,

40 reviewed and analysed the literature, and wrote the manuscript. All authors gave final approval

41 for publication. 


\section{Acknowledgements}

43 We acknowledge Curt Lively for useful discussions on the history and development of the Red

44 Queen hypothesis for sex and members of the Neiman lab as well as several anonymous

45 reviewers and Associate Editor Britt Koskella for helpful comments on earlier versions of the

46 MS. TS was supported by SNSF grant PP00P3 139013.

\section{Data archival location}

The results of our literature survey are provided as electronic supplementary material.

\section{Abstract}

52 Why and how sexual reproduction is maintained in natural populations, the so-called "queen of

53 problems", is a key unanswered question in evolutionary biology. Recent efforts to solve the

54 problem of sex have often emphasized results generated from laboratory settings. Here, we use a

55 survey of representative "sex in the wild" literature to review and synthesize the outcomes of

56 empirical studies focused on natural populations. Especially notable results included relatively

57 strong support for mechanisms involving niche differentiation and a near absence of attention to

58 adaptive evolution. Support for a major role of parasites is largely confined to a single study

59 system, and only three systems contribute most of the support for mutation accumulation

60 hypotheses. This evidence for taxon specificity suggests that outcomes of particular studies

61 should not be more broadly extrapolated without extreme caution. We conclude by suggesting

62 steps forward, highlighting tests of niche differentiation mechanisms in both lab and nature and

63 empirical evaluation of adaptive evolution-focused hypotheses in the wild. We also emphasize

64 the value of leveraging the growing body of genomic resources for non-model taxa to address

65 whether the clearance of harmful mutations and spread of beneficial variants in natural

66 populations proceeds as expected under various hypotheses for sex. 


\section{Introduction}

68 Ask evolutionary biologists about unresolved problems in evolution, and many will question

69 why so many eukaryotic species produce offspring via sexual reproduction ("sex"). The

70 predominance of sex was first identified as a major unanswered question by leading twentieth

71 century evolutionary biologists such as George Williams and John Maynard Smith, who

72 developed theory demonstrating that sexual reproduction should be at a substantial disadvantage

73 vis-à-vis asexual reproduction and thus be rapidly replaced by the latter (Maynard Smith 1971,

74 1978, Williams 1975). This theory is based on the recognition that sex can impose a variety of

75 costs (e.g., males, recombination, for a recent overview see Lehtonen et al. 2012, Meirmans et al.

76 2012) that should translate into major advantages for asexual reproduction. The central place of

77 the problem of sexual reproduction in evolutionary theory is illustrated by Graham Bell's 1982

78 statement that the maintenance of sex is the "queen of problems" in evolutionary biology (Bell

79 1982). Within a decade or so after the paradox of sexual reproduction was first identified, dozens

80 of hypotheses for sex had been proposed (Kondrashov 1993). Most of these hypotheses focused

81 on direct or indirect benefits of sexual reproduction that can outweigh (at least in principle) the

82 costs of sex (reviewed in Neiman and Schwander 2011) and that are linked to genetic

83 consequences of meiotic recombination and segregation (e.g., Agrawal 2009a,b). Despite all of

84 this attention and the forty or so years that have passed since the problem of sex was identified,

85 the evolutionary mechanisms underlying the maintenance of sex are still unclear (e.g., Sharp and

86 Otto 2016, Neiman et al. 2017).

87 The crux of the problem of the maintenance of sex is the persistence of sexual

88 reproduction in so many species, and especially the maintenance of sex in natural populations of

89 organisms or lineages that can use asexual reproduction to produce offspring. Even so, most 
90 recent attention towards empirical tests of mechanisms favoring sex has focused on results

91 generated by experimental evolution in laboratory settings. Laboratory studies, which nearly

92 always use genetic model systems (e.g., Drosophila melanogaster (Singh et al. 2015),

93 Saccharomyces cerevisiae (McDonald et al. 2016), Tribolium castaneum (Lumley et al. 2015),

94 Brachionus calyciflorus (Becks and Agrawal 2012)), are very powerful because the focal

95 mechanisms can be manipulated and isolated. Indeed, lab-focused studies have provided

96 important tests of the potential for particular mechanisms for sex to be applicable under specific

97 circumstances (e.g., sexual selection-facilitated clearance of mutational load, strong selection for

98 adaptation to new environments; reviewed in Sharp and Otto 2016).

A critical complement to these insights from the laboratory will come from

100 characterization of the mechanisms contributing to the maintenance of sex in natural populations.

101 In particular, despite the rigor and elegance of many laboratory studies, it can be difficult to

102 determine whether their outcomes can be extrapolated to natural conditions. This challenge is

103 exemplified by a recent example of a case where field and lab studies addressing the same

104 mechanisms for sex generated opposite results (Lavanchy et al. 2016).

105 There are multiple and non-mutually exclusive potential explanations for differences

106 between the outcomes of laboratory and field studies. One important consideration is that model

107 organisms are characterized by short generation times, large populations, and small body sizes,

108 which is not representative of the bulk of metazoans. Model organisms are also often the

109 products of decades of laboratory culture and thus are almost certainly adapted to laboratory

110 conditions (e.g., Sterken et al. 2015). It is also impossible to perform laboratory-based studies

111 featuring all factors that are likely relevant to the realized costs and benefits of sexual

112 reproduction, including locally adapted parasites and predators, competitors for limited 
113 resources, extreme abiotic conditions, and unpredictable environmental changes. An additional

114 challenge is that the inclusion of these factors in laboratory experiments can translate into

115 conditions that are unlikely to characterize natural populations, e.g., unrealistically high doses of

116 infectious parasites or the imposition of direct competition between sexual and asexual

117 individuals that experience niche differentiation in the wild. While studies focused on natural

118 populations, and in particular, field-based studies, are more realistic, they cannot match lab

119 studies with respect to the ability to control variables and achieve causal inference. The take-

120 home message is that the insights from field and laboratory studies ultimately need to be

121 integrated in order to produce robust insights into natural patterns and processes.

122 Here, we provide a synthetic overview of "sex in the wild" studies, the first of which we

123 are aware since Bell (1982). We addressed this goal by performing a survey of directly relevant

124 empirical literature to (1) assess the contributions of field studies towards resolving the sex

125 problem, (2) identify what we have learned from these studies and what we still need to know,

126 and (3) provide some concrete steps forward.

\section{Methods}

\section{Literature survey approach}

129 We began our survey by establishing a set of a priori criteria for study inclusion. These criteria

130 were formulated with the goal of only including studies that could directly inform the

131 maintenance of sex in natural populations. First of all, this meant that the study had to be

132 performed in the field or use field-collected individuals that were not subsequently subject to the

133 potential for selection in a laboratory environment. We included studies with laboratory-reared

134 individuals only in those cases where lab rearing was unlikely to influence the factors that are the 
135 focus of testing (e.g., establishment of phylogenetic relationships). We therefore excluded

136 studies where the potential for laboratory-imposed selection could confound the ability to

137 interpret the study outcome, e.g. via laboratory-cultured lineages (e.g., Xu et al. 2011).

138 Second, we confined our survey to studies explicitly focused on investigating a particular

139 mechanism for the maintenance of sex. We chose to adopt this mechanism-centered approach

140 because this type of research takes place in a structured framework that facilitates meaningful

141 comparisons among studies. Our strategy does have some limitations in excluding other valuable

142 types of studies, including but not limited to evaluation of population genetic principles in

143 natural populations (e.g., Menken et al. 1995, Lo et al. 2009), establishing the biogeographic

144 distribution of sexual vs. asexual reproduction (e.g., geographic parthenogenesis; see Tilquin and

145 Kokko 2016 for a recent overview), or describing unusual natural manifestations of reproductive

146 strategies (e.g., Aanen et al. 2016).

$147 \quad$ Finally, we only included studies featuring obligately asexual individuals and

148 facultatively or obligately sexual individuals that are sympatric in nature in at least part of their

149 range. We made this choice because our goal is to identify the mechanisms that underlie the

150 maintenance of sex in natural populations. Field-based studies in systems that feature

151 sexual/asexual sympatry mean that the sexuals and asexuals can experience direct competition

152 and allow for the most direct comparisons (with the fewest confounding factors) between

153 reproductive modes. We do acknowledge that this particular approach does have limitations,

154 such as the inability to directly address why some sexual lineages are not subject to invasion by

155 asexual counterparts. We excluded all studies of sperm-dependent asexual taxa (e.g., Ambystoma

156 mole salamanders, Ips bark beetles, Rubus subgenus Rubus blackberries) because all-asexual

157 populations of sperm-dependent organisms are not evolutionarily stable. 
We then classified and described each study according to the mechanism that the study

159 addressed (as outlined below), the methods used, the study outcomes, whether the study

160 supported or did not support the focal mechanism, and the taxonomic group represented by the

161 focal organisms (see supplementary material; Table S1). We included an "Other" category to

162 account for studies that addressed mechanisms or conditions with the potential to favor sex that

163 did not easily fit under the umbrella of an established mechanism (e.g., reproductive assurance,

164 which is largely confined to asexuals but needs to be tested by comparing sexuals and asexuals).

165 We classified the species by class, following the U.S. Interagency Taxonomic Information

166 System; when species from multiple classes were addressed, we used the lowest shared

167 taxonomic level.

168 We included individual studies in more than one mechanism category if (a) the study

169 found evidence for or against multiple mechanisms or (b) whether and how the study tested

170 mechanisms was not clear enough to identify a single mechanism that was the focus of the paper.

171 In the latter situation, we assessed each study carefully and then assigned the study to each

172 mechanism that in our view was tested by the study design and/or was supported by the evidence

173 delivered by the study. We termed each incidence of a distinct test of a distinct mechanism a

174 "case", which meant that some studies are represented by more than one case. We use this

175 terminology consistently throughout the rest of the paper. We concluded our survey at the end of

176 the summer of 2017, meaning that only papers published by this time were able to be included.

178 Mechanisms underlying the benefits of sex

179 Sex, via segregation and recombination, breaks up linkage disequilibria (LD) across loci (Hill

180 and Robertson 1966). This consequence of sexual reproduction is the reason that most 
181 mechanisms for the maintenance of sex focus on identifying conditions or situations associated

182 with benefits of breaking up LD. Theoretical analyses have highlighted situations where

183 selection changes over time and/or space or when linkage is generated by the combination of

184 selection and drift as the conditions that are most likely to produce such benefits (Barton 2009).

185 Field-based studies of sex that address benefits of LD breakup have typically focused on

186 ecological situations (e.g., coevolving parasites or spatially structured niches, see below) that are

187 expected to translate into changes in selection over space or time, but do not generally establish

188 explicit links to the genetic mechanisms conferring benefits to sex. For this reason we a priori

189 delineated the major mechanisms for sex by ecological mechanisms or scenarios that can

190 generate or are associated with changes in selection.

191 We acknowledge several limitations of our approach to mechanism characterization.

192 First, some of these categories feature conceptual overlap (e.g., "parasites" and "increased rate of

193 adaptive evolution”, from the perspective that sexuals that can adapt more quickly to parasites

194 might be at an advantage), while other categories could be combined to make even broader

195 categories (e.g., all niche-based mechanisms; all hypotheses generated by genetic linkage).

196 Second, it is virtually certain that some evolutionary biologists would produce different

197 classification systems. Finally, we decided to separate mechanisms involving disadvantages to

198 asexual lineages via reduced rates of adaptive evolution and increased rates of harmful mutation

199 accumulation into separate categories. Although both phenomena are the consequence of the

200 reduced efficacy of selection at linked sites (Hill-Robertson effect; Hill and Robertson 1966,

201 Felsenstein 1974), different empirical methods are typically applied to detect evidence for

202 ineffective adaptive evolution vs. ineffective purifying selection. 


\section{Parasites}

204 Biological antagonism - what we henceforth refer to as "parasites" or parasite pressure"- is

205 potentially connected to the maintenance of sex because parasites can generate rapid changes in

206 the direction of selection. The most prominent of the parasite mechanisms is the "Red Queen"

207 (Bell 1982, Jaenike 1978, Hamilton 1980), under which parasites can help maintain sex by

208 imposing negative frequency-dependent selection favoring rare host genotypes. Links between

209 sex and biological antagonism can be driven by other mechanisms (e.g., Haafke et al. 2016),

210 though the Red Queen-sex connection seems to be the most theoretically robust (e.g., Hamilton

211 et al. 1990, Howard and Lively 1994, Peters and Lively 1999) and has received more empirical

212 attention and support than other parasite-driven mechanisms for sex (reviewed in Neiman and

213 Koskella 2009, Lively and Morran 2014).

\section{Rate of adaptive evolution}

215 Selection works most effectively if beneficial and deleterious mutations occur in different

216 individuals because these individuals should experience larger differentials in relative fitness

217 than when mutations with opposite fitness effects co-occur within individuals (Hill and

218 Robertson 1966). Over time, drift in the presence of selection may therefore lead to the

219 accumulation of genomes where favorable and harmful alleles are linked. Sex can generate

220 benefits in this situation in two ways: by immediately exposing 'hidden variation' (both

221 favorable and harmful) to selection and by enabling more effective adaptive evolution at longer

222 time scales. 


\section{Harmful mutations}

224 Hill-Robertson effects are expected to translate into increased rates of harmful mutation

225 accumulation via relatively ineffective purifying selection in asexual vs. sexual lineages.

226 Muller's ratchet, which will cause irreversible mutation accumulation in small populations, is

227 also expected to disproportionately affect asexual lineages (Muller 1964).

229 One of the simplest mechanisms that enables coexistence between asexuals and their sexual

230 relatives is niche differentiation. In the most extreme case of non-overlapping sexual and asexual

231 niches, there is no competition between sexuals and asexuals, rendering costs of sex irrelevant

232 (Meirmans et al. 2012). Perhaps because of its simplicity, there exist only a few theory-focused

233 papers on this topic. One exception is the modelling study by Case and Taper (1986), who

234 showed that niche differentiation can arise through character displacement after invasion of a

235 sexual population by an asexual lineage. In practice, however, this mechanism is difficult to test:

236 it is challenging to estimate the degree of niche overlap in natural populations and to determine

237 whether the observed degree of niche differentiation between sexuals and asexuals is enough to

238 prevent competition-driven extinction of one of the reproductive modes.

\section{$239 \quad$ Niche breadth}

240 There are a variety of formulations of the overarching mechanism that sex can be maintained in

241 situations where sexual individuals, lineages, or populations cover larger fractions of the

242 available niche space than asexual counterparts. The most prominent example is the Tangled

243 Bank hypothesis (Bell 1982), which postulates that sexual reproduction can be favored by

244 generating a genetically diverse set of offspring that can make efficient use of a heterogeneous 
245 habitat via reduction in competition between siblings for limited resources. Asexually produced

246 siblings, on the other hand, will compete for these same resources because they are genetically

247 similar (also predicted by the conceptually similar frozen niche concept (Vrijenhoek 1979)). This

248 advantage of sexual reproduction is increasingly offset as asexual lineage diversity increases,

249 assuming that higher asexual diversity translates into more variable resource utilization by the

250 asexual population.

\section{Results}

252 Our literature survey of 66 studies (83 cases; some studies focused on multiple mechanisms)

253 addressing the mechanisms underlying the maintenance of sex in the wild revealed some clear

254 patterns (Table 1). First, there is a distinct majority of support (56 cases) vs. lack of support (27

255 cases), perhaps reflecting a publication bias towards positive results. The parasite and niche

256 differentiation mechanisms predominated amongst the studies featuring positive results; we

257 elaborate on these and other mechanism-specific patterns below. Our survey also clearly showed

258 that some taxa have been the focus of far more investigation than others. The vast majority of

259 studies involved animal systems (54 studies; 82\%), which themselves were dominated by

260 gastropods (23 studies), branchiopods (eight studies), reptiles (eight studies), and insects (six

261 studies). The remaining $16 \%$ of the studies were in plants (11 studies; all

262 Magnoliopsida/angiosperms) and fungi (one study). Some systems were particularly heavily

263 represented. For example, the gastropod Potamopyrgus antipodarum was featured in 16 studies

264 (see supplementary material, Table S1, for an overview). Other taxa common in our survey

265 included the branchiopod Daphnia pulex (seven studies), the gastropod Melanoides tuberculata

266 (four studies), and the angiosperm Taraxacum officinale (four studies). Only two studies applied 
267 a broad taxonomic approach, using comparisons of the ecologies of hundreds of sexual and

268 asexual taxa (Ross et al. 2013, van der Kooi et al. 2017) to detect associations with, or

269 consequences of, reproductive mode variation that apply across taxa.

270 Parasites

271 Our search revealed 30 cases (representing 29 studies; one study with mixed results contributed

272 two cases) that considered the maintenance of sex from the perspective of selection imposed via

273 parasitism, by far the most frequently tested of the five main mechanism categories that we

274 distinguished. Twenty of these cases reported results consistent with the expectations of

275 situations where parasites are contributing to the maintenance of sex. Nearly all cases (27/30)

276 focused at least in part on the Red Queen. A distinct majority of these Red Queen cases (15/27)

277 involved the interaction between the snail Potamopyrgus antipodarum and the trematode parasite

278 Microphallus 'livelyi'. The three parasite-focused papers that did not explicitly address the Red

279 Queen considered broader formulations of the parasite/antagonism mechanism (e.g., "parasitism

280 rate", "herbivory").

\section{Rate of adaptive evolution}

282 Our survey identified only three cases that addressed rates of adaptive evolution in the context of

283 the maintenance of sex. All three of these cases took what we viewed as indirect approaches to

284 this question, addressing whether sexuals were more often found in unpredictable abiotic

285 environments that would likely demand rapid adaptation relative to the environments harboring

286 asexual counterparts. Two ostracod-focused cases reported evidence consistent with this

287 prediction, with sexual ostracods associated with relatively harsh and unpredictable

288 environments (Schmit et al. 2013a,b). By contrast, parasites seemed to be a more likely 
explanation of patterns of distribution of sexual vs. asexual New Zealand freshwater snails than

290 rapidly changing abiotic components of the environment (Lively 1987). Direct empirical

291 evaluation of whether sexual organisms feature higher rates of adaptive evolution than their

292 asexual relatives in natural populations clearly deserves future attention. Despite ample evidence

293 for the importance of drift in natural populations (e.g., all studies supporting the 'mutation

294 accumulation' mechanism), we found no field-based studies that investigated whether sex

295 generates short-term benefits by exposing hidden genetic variation to selection.

\section{Mutation accumulation}

297 The prediction that deleterious mutations accumulate more rapidly in asexual than sexual

298 lineages has been tested in multiple taxa. Most cases (14 out of 19 cases; Table 1) were

299 consistent with a scenario where asexuals accumulate deleterious mutations more rapidly than

300 sexual lineages. Even so, nearly all (15/19) cases are based on a handful of genes, raising the

301 question of the extent to which these results are likely to hold for the genome as a whole. Only

302 four studies extended analyses of deleterious mutation accumulation to the genome scale

303 (Hollister et al. 2015, Ament-Velásquez et al. 2016, Brandt et al. 2017, Lovell et al. 2017). Three

304 of these studies (Hollister et al. 2015, Ament-Velásquez et al. 2016, Lovell et al. 2017) found

305 that, as expected, asexuals had a higher load of deleterious mutations than sexuals. The fourth

306 study (Brandt et al. 2017) found that sexual taxa experienced more mutation accumulation than

307 asexual counterparts. This latter study focused on asexual lineages that are extremely old (tens of

308 million years since derivation from sexual ancestors), suggesting that the absence of deleterious

309 mutation accumulation may have contributed to the long-term persistence of these lineages in the

310 absence of sex. 


\section{$311 \quad$ Niche differentiation}

312 We identified 17 cases that considered the maintenance of sex from the perspective of niche

313 differentiation. Together with harmful mutations, these studies featured the broadest taxonomic

314 support of the mechanism categories, representing six of the 11 taxonomic classes in Table 1.

315 Tests for niche differentiation were most common in angiosperms, representing six of 17 cases.

316 Thirteen of these 17 cases found at least some support for niche differentiation between sexuals

317 and asexuals. Only three of these cases took the critical and perhaps most challenging additional

318 step of determining whether the observed niche differentiation is enough to eliminate

319 competition between sexuals and asexuals (O'Connell and Eckert 2001, Lehto and Haag 2010,

320 Schmit et al. 2013a). All three cases did indeed suggest that niche differentiation between

321 sexuals and asexuals was substantial enough that direct competition is unlikely, which should in

322 turn resolve the problem of sex by rendering costs of sex irrelevant.

\section{Niche breadth}

324 We identified eight cases where niche breadth was compared between asexual taxa and sexual

325 counterparts, representing five taxonomic groups. In all but one case, the asexuals were

326 characterized by broader niches than their sexual relatives. While most of these studies just

327 focused on one or a few systems, the two studies that evaluated hundreds of species reported the

328 same pattern (Ross et al. 2013, van der Kooi et al. 2017). Because the maintenance of sex via

329 differential coverage of niche space requires that sexuals cover more niche space (and not, as

330 found here, asexuals), our survey suggests that niche-breadth related mechanisms generally do

331 not contribute to the maintenance of sex in the wild. 


\section{Discussion}

333 Perhaps most prominently, our survey revealed an important role for niche differentiation

334 mechanisms in the maintenance of sex. This finding is also consistent with the many examples of

335 geographical parthenogenesis and the observation that sexual and asexual individuals or lineages

336 often differ in other key elements of their biology or ecology (e.g., hybrid status, polyploidy,

337 production of resting eggs) (see also Meirmans et al. 2012). It is important to note that our

338 survey revealed pervasive niche differentiation between sexuals and asexuals even in the

339 exclusion of all studies focused on sexual and asexual taxa with non-overlapping ranges. While

340 including these latter studies would perhaps have suggested an even stronger pattern of niche

341 differentiation, without sympatric sexuals and asexuals, it is impossible to determine whether

342 niche differentiation is a consequence of evolutionary divergence (character displacement

343 following competition between sexual and asexual lineages) versus other factors such as

344 biogeographic history (secondary contact). Evidence for the potential importance of niche

345 differentiation from the field is striking because this mechanism has not otherwise received

346 prominent attention in reviews on the benefits of sex (see Sharp and Otto (2016) for a recent

347 example). We suspect that this inattention might be at least in part linked to the scarcity of

348 theoretical studies on niche differentiation.

349 In contrast to niche differentiation, there was very little support for the related but distinct

350 niche breadth mechanisms such as Tangled Bank (Bell 1982). While this type of mechanism has

351 received quite a bit of theoretical attention (e.g., Bell 1982, Case and Taper 1986, Pound et al.

352 2002), they seem to have very little empirical backing: in our survey, we found seven examples

353 of negative results and only one example of support among the eight niche breadth-focused cases

354 in our survey. This finding is in agreement with the general sentiment from earlier sex-focused 
research that revealed little evidence for Tangled Bank-like mechanisms (Ellstrand and

356

357

358

359

360

361

362

363

364

365

366

367

368

369

370

371

372

373

374

375

376

377

Antonovics 1985, Burt and Bell 1987, but see Song et al 2011).

Another striking finding of our study was the absence of field studies focused on testing whether an increased rate of adaptive evolution might help favor sexual over asexual organisms.

While there is substantial theoretical (Barton 1995, Burt 2000) and lab-based (e.g., Kaltz and

Bell 2002, Goddard et al. 2005, McDonald et al. 2016) support for an important role for sexual

reproduction in facilitating adaptive evolution, we only found three field-based studies that

directly addressed whether sexuals have an adaptability advantage relative to asexual

counterparts. One likely explanation for this distinct difference is that adaptability hypotheses are

more difficult to rigorously test in the wild and are thus difficult to propose, fund, or execute. We

also cannot exclude the possibility that publication bias (e.g., the challenges in publishing

negative results) plays a role here or throughout our survey.

Most of the positive evidence in our survey comes from studies addressing the Red

Queen hypothesis, a particular formulation of the parasite mechanism for sex. A distinct majority

of these Red Queen-focused studies found evidence that parasite-host interactions contribute to

the maintenance of sex. While the relatively large number and generally positive outcome of

these studies might be taken as evidence that the Red Queen can provide a general explanation

for the maintenance of sex in natural populations, the fact that most of these cases $(15 / 27$;

$\sim 55 \%$ ) involve a single study system, Potamopyrgus antipodarum, means that this conclusion

would be premature. The issues posed by dominance of a particular study system with respect to

tests of a particular mechanism are highlighted by the fact that $15 / 15$ cases in the Potamopyrgus

system are consistent with the expectations of the Red Queen, compared to only five of 12 cases

from other taxa (see Table S1 for more details). The problem of non-independence that arises 
378 from multiple tests of the same mechanism in the same system are heightened when, as for many

379 sexual/asexual systems, there is only one transition to asexual reproduction, and thus, only one

380 possible phylogenetically independent comparison. In general, our take-home message is that

381 emergence of any mechanism as one that confers broad explanatory power for understanding sex

382 in nature will require support from a diverse array of natural systems.

While many cases (12/17) provide at least some support for mutation accumulation

384 mechanisms, most of the confirmatory evidence comes from only three study systems: Daphnia,

385 Potamopyrgus, and Campeloma. All directly relevant genome-scale analyses of deleterious

386 mutation accumulation of which we are aware have found considerable among-gene variation

387 with respect to the rate of deleterious mutation accumulation in sexual and asexual lineages.

388 Because of this among-gene variation, the inferences generated by the 15 cases that only

389 included a handful of genes must be viewed with caution. Indeed, one of the four cases that did

390 investigate mutation accumulation at the whole-genome scale in the wild found that, contrary to

391 predictions, sexual taxa experienced more mutation accumulation (Brandt et al. 2017). Finally,

392 although there appears to be some general support for deleterious mutation accumulation in

393 asexual lineages, it is important to note that this mechanism is unlikely to explain the

394 maintenance of sex. The reason for this caveat is that mutation accumulation generates a long-

395 term disadvantage for asexuality, whereas short-term advantages are required for the

396 maintenance of sex within populations (Maynard Smith 1978).

$397 \quad$ No single mechanism emerged as being important to the maintenance of sex across all

398 natural systems included in our survey. This result provides indirect support for the idea that

399 different mechanisms for sex might be important for different taxa (see also Neiman et al. 2017).

400 While the notion that multiple mechanisms are of relevance to the maintenance of sex in nature 
would not surprise most of the researchers who study this topic, our survey results emphasize the importance of including a variety of taxa and considering multiple mechanisms when studying

403 the maintenance of sex. Direct tests of the importance of this type of pluralism are conceptually

404 simple but logistically challenging: the simultaneous study of multiple mechanisms across a 405 diverse array of appropriate taxa in natural settings. The related but distinct point regarding the 406 existence of a variety of different evolutionary "schools" concerning the maintenance of sex 407 (Gouyon 1999, Meirmans and Strand 2010) also highlights the value of research on the same 408 mechanisms or systems by multiple independent investigator groups.

\section{Outlook}

410 Important steps forward for field-based research on the maintenance of sex will ideally come

411 from several angles, which should perhaps most prominently include rigorous evaluation of the

412 Red Queen hypothesis for sex in a diverse array of systems and direct tests for adaptive evolution

413 (especially short-term effects) in natural settings. Especially insightful results with respect to the

414 latter could be obtained from field experiments where sexuals and asexuals are transferred to (1)

415 relatively harsh and/or unpredictable habitats, and (2) a relatively stable habitat, and where

416 adaptation to the environment is tracked over multiple generations (see Lavanchy et al. 2016 for

417 an example). Other useful tests could come from creative leveraging of unpredictable events

418 (e.g., floods, fire, or even climate change) that might be expected to enable the detection of rapid

419 adaption. Finally, researchers could evaluate whether sex generates short-term benefits in natural

420 populations via the exposure of hidden genetic variation to selection by comparing genetic

421 variation for fitness in naturally occurring and coexisting sexual and asexual organisms over 422 multiple generations. 
With respect to other mechanisms for the maintenance of sex, our study suggests that

424 broader attention to niche differentiation mechanisms would likely turn out to be fruitful. In

425 particular, the application of mesocosm approaches that reasonably reflect inherent natural

426 complexity could bridge field and laboratory insights (e.g., Ganz and Ebert 2010). Throughout,

427 we expect that an increasing availability of genomic resources for non-model taxa that have

428 achieved prominence as the focus of "sex in the wild" studies (e.g., Potamopyrgus antipodarum

429 (Bankers et al. 2017); Taraxacum officinale, E. Schranz pers. comm.) will provide a critical

430 means of testing mechanisms for sex that make specific predictions regarding molecular

431 evolution. We also believe that "pluralist" approaches that explicitly consider the possibility that

432 different mechanisms might be important for different taxa or that separate mechanisms can

433 operate simultaneously or in concert will provide key advances (Neiman et al. 2017). Finally, our

434 study invites a formal comparison of outcomes of field versus laboratory studies that address the

435 maintenance of sex. Evaluating whether lab studies consistently deliver similar vs. different

436 outcomes than field studies with respect to particular mechanisms or taxa would be especially

437 illuminating.

\section{References}

439 Aanen D, Beekman M, Kokko H. 2016 Introduction: Weird sex: the underappreciated diversity 440 of sexual reproduction Phil. Trans. R. Soc. B 371, 20160262.

441 Agh N, Abatzopoulos TJ, Kappas I, Van Stappen G, Razavi Rouhani SM, Sorgeloos P. 2007

442 Coexistence of sexual and parthenogenetic Artemia populations in Lake Urmia and neighboring

443 lagoons. Int. Rev. Hydrobiol. 92, 48-60.

444 Agrawal AF. 2009a Differences between selection on sex versus recombination in Red Queen 445 models with diploid hosts. Evolution 63, 2131-2141. 
Agrawal AF. 2009b Spatial heterogeneity and the evolution of sex in diploids. Am. Nat. 174, S54-S70.

448 Ament-Velásquez SL, Figuet E, Ballenghien M, Zattara EE, Norenburg JL, Fernández-Álvarez, Bierne J, Bierne N, Galtier N. 2016. Population genomics of sexual and asexual lineages in fissiparous ribbon worms (Lineus, Nemertea): hybridization, polyploidy and the Meselson effect. Mol. Ecol. 25, 3356-3369.

Bankers L, Fields P, McElroy KE, Boore JL, Logsdon JM Jr, Neiman M. 2017 Genomic evidence for population-specific responses to co-evolving parasites in a New Zealand freshwater snail. Mol. Ecol. 26, 3663-3675. against deleterious mutations in cytochrome oxidase I of asexual bdelloid rotifers. Mol. Biol. Evol. 24, 1952-1962.

Barton NH. 1995 A general model for the evolution of recombination. Genet. Res. 65, 123-144.

Barton NH. 2009 Why sex and recombination? Cold Spring Harb. Symp. Quant. Biol 74, 187-95.

460 Bast J, Schaefer I, Schwander T, Maraun M, Scheu S, Kraaijeveld K. 2016 No accumulation of 461 transposable elements in asexual arthropods. Mol. Biol. Evol. 33, 697-706.

462 Becks L, Agrawal AF. 2012 The evolution of sex is favoured during adaptation to new 463 environments. PLoS Biol. 10, e1001317.

464 Bell G. 1982 The masterpiece of nature. London, UK: Croon Helm.

465 Ben-Ami F, Heller J. 2008 Sex versus parasitism versus density. Biol. J. Linn. Soc. 93, 537-544.

466 Ben-Ami F, Heller J. 2005 Spatial and temporal patterns of parthenogenesis and parasitism in the freshwater snail Melanoides tuberculata. J. Evol. Biol. 18, 138-146.

468 Ben-Ami F, Heller J. 2007 Temporal patterns of geographic parthenogenesis in a freshwater 469 snail. Biol. J. Linn. Soc. 91, 711-718.

470 Brandt A, Schaefer I, Glanz J, Schwander T, Maraun M, Scheu S, Bast J. 2017. Effective 471 purifying selection in ancient asexual oribatid mites. Nat. Comm 8, 873.

472 Brown SG, Kwan S, Shero S. 1995 The parasitic theory of sexual reproduction: parasitism in 473 unisexual and bisexual geckos. Proc. Roy. Soc. Lond. B 260, 317-320.

474 Bruvo R, Adolfsson S, Symonova R, Lamatsch DK, Schön I, Jokela J, Butlin RK, Müller S. 4752010 Few parasites, and no evidence for Wolbachia infections, in a freshwater ostracod 476 inhabiting temporary ponds. Biol. J. Linn. Soc. 102, 208-216. 
Burt A. 2000 Perspective: sex, recombination, and the efficacy of selection - was Weismann right? Evolution 54, 337-351.

Burt A, Bell G. 1987 Mammalian chiasma frequencies as a test of two theories of recombination.

481 Case TJ. 1990 Patterns of coexistence in sexual and asexual species of Cnemidophorus lizards.

482 Oecologia 83, 220-227.

483 Case TJ, Taper ML. 1986 On the coexistence and coevolution of asexual and sexual competitors. 484 Evolution 40, 366-387.

485 Crummett LT, Sears BF, Lafon DC, Wayne ML. 2013 Parthenogenetic populations of the 486 freshwater snail Campeloma limum occupy habitats with fewer environmental stressors than 487 their sexual counterparts. Freshw. Biol. 58, 655-663.

488 Cuellar O. 1979 On the ecology of coexistence in parthenogenetic and bisexual lizards of the 489 genus Cnemidophorus. Am. Zool., 19, 773-786.

490 Dagan Y, Liljeroos K, Jokela J, Ben-Ami F. 2013 Clonal diversity driven by parasitism in a 491 freshwater snail. J. Evol. Biol. 26, 2509-2519.

Dybdahl MF, Lively CM. 1995 Host-parasite interactions: infection of common clones in natural populations of a freshwater snail (Potamopyrgus antipodarum). Proc. Roy. Soc. Lond. B Biol.

494 Sci. 260, 99-103.

Dybdahl MF, Lively CM. 1998 Host-parasite coevolution: evidence for rare advantage and time-

497 Ellstrand NC, Antonovics J. 1985 Experimental studies of the evolutionary significance of sexual 498 reproduction II. A test of the density-dependent selection hypothesis. Evolution 39, 657-666.

499 Elzinga JA, Chevasco V, Mappes J, Grapputo A. 2012 Low parasitism rates in parthenogenetic 500 bagworm moths do not support the parasite hypothesis for sex. J. Evol. Biol. 25, 2547-2558.

501 Felsenstein J. 1974 The evolutionary advantage of recombination. Genetics 78, 737-756.

502 Fox JA, Dybdahl MF, Jokela J, Lively CM. 1996 Genetic structure of coexisting sexual and 503 clonal subpopulations in a freshwater snail (Potamopyrgus antipodarum). Evolution 50, 15415041548.

505 Ganz HH, Ebert D. 2010 Benefits of host genetic diversity for resistance to infection depend on 506 parasite diversity. Ecology 91, 1263-1268.

507 Gibson AK, Xu JY, Lively CM. 2016 Within-population covariation between sexual

508 reproduction and susceptibility to local parasites. Evolution 70, 2049-2060. 
509 Goddard MR, Godfray H, Burt A. 2005. Sex increases the efficacy of natural selection in 510 experimental yeast populations. Nature 434, 636-40.

511 Gouyon, P-H. 1999 Sex: a pluralistic approach includes species selection. (One step beyond and 512 it's good.). J. Evol. Biol. 12, 1029-1030.

513 Grishkan I, Korol AB, Nevo E, Wasser SP. 2003 Ecological stress and sex evolution in soil 514 microfungi. Proc. Roy. Soc. Lond. B Biol. Sci. 270, 13-18.

515 Haafke J, Chakra MA, Becks L. 2016 Eco-evolutionary feedback promotes Red Queen dynamics 516 and selects for sex in predator populations. Evolution 70, 641-652.

517 Hamilton WD. 1980 Sex vs. non-sex vs. parasite. Oikos 35, 282-290.

518 Hamilton WD, Axelrod R, Tanese R. 1990 Sexual reproduction as an adaptation to resist 519 parasites (A review). Proc. Nat. Acad. Sci. USA 87, 3566-3573.

520 Hanley KA, Bolger DT, Case TJ. 1994 Comparative ecology of sexual and asexual gecko 521 species (Lepidodactylus) in French Polynesia. Evol. Ecol. 8, 438-454.

522 Hanley KA, Fisher RN, Case TJ. 1995 Lower mite infestations in an asexual gecko compared 523 with its sexual ancestors. Evolution 49, 418-426.

524 Henry L, Schwander T, Crespi BJ. 2012 Deleterious mutation accumulation in asexual Timema 525 stick insects. Mol. Biol. Evol. 29, 401-408.

526 Hill WG, Robertson A. 1966 The effect of linkage on limits to artificial selection. Genet. Res. 8, 527 269-294.

528 Hollister JD, Greiner S, Wang W, Wang J, Zhang Y, Wong GK, Wright SI, Johnson MT. 2015. 529 Recurrent loss of sex is associated with accumulation of deleterious mutations in Oenothera.

530 Mol. Biol. Evol. 32, 896-905.

531 Howard RS, Lively CM. 1994 Parasitism, mutation accumulation, and the maintenance of sex. 532 Nature 367, 554-557.

533 Innes DJ, Ginn M. 2014 A population of sexual Daphnia pulex resists invasion by asexual 534 clones. Proc. Roy. Soc. Lond. B 281, 20140564.

535 Jaenike J. 1978 An hypothesis to account for the maintenance of sex within populations. Evol. 536 Theor. 3, 191-194.

537 Jiang X, Tang H, Ye Z, Lynch M. 2017 Insertion polymorphisms of mobile genetic elements in 538 sexual and asexual populations of Daphnia pulex. Genome Biol. Evol. 9, 362-374. 
Johnson SG. 1994 Parasitism, reproductive assurance and the evolution of reproductive mode in a fresh-water snail. Proc. Roy. Soc. Lond. B Biol. Sci. 255, 209-213.

541 Johnson SG, Howard RS. 2007 Contrasting patterns of synonymous and nonsynonymous

542 sequence evolution in asexual and sexual freshwater snail lineages. Evolution 61, 2728-2735.

543 Johnson MTJ, Smith SD, Rausher MD. 2009 Plant sex and the evolution of plant defenses

544 against herbivores. Proc. Nat. Acad. Sci. USA 106, 18079-18084.

545 Jokela J, Lively CM. 1995 Parasites, sex, and early reproduction in a mixed population of 546 freshwater snails. Evolution 49, 1268-1271.

547 Jokela J, Dybdahl MF, Lively CM. 2009 The maintenance of sex, clonal dynamics, and host-

548 parasite coevolution in a mixed population of sexual and asexual snails. Am. Nat. 174, S43-S53.

549 Kaltz O, Bell G. 2002. The ecology and genetics of fitness in Chlamydomonas. XII. Repeated 550 sexual episodes increase rates of adaptation to novel environments. Evolution 56, 1743-1753.

551 Kearney MR, Moussalli A, Strasburg J, Lindenmayer D, Moritz C. 2003 Geographic

552 parthenogenesis in the Australia arid zone: I. A climatic analysis of the Heteronotia binoei

553 complex (Gekkonidae). Evol. Ecol. Res. 5, 953-976.

554 Killick SC, Obbard DJ, West SA, Little TJ. 2008 Parasitism and breeding system variation in 555 North American populations of Daphnia pulex. Ecol. Res. 23, 235-240.

556 King KC, Lively CM. 2009 Geographic variation in sterilizing parasite species and the Red 557 Queen. Oikos 118, 1416-1420.

558 King KC, Jokela J, Lively CM. 2011 Parasites, sex, and clonal diversity in natural snail 559 populations. Evolution 65, 1474-1481.

560 Kondrashov AS. 1993 Classification of hypotheses on the advantage of amphimixis. J. Hered. $561 \quad 84,372-387$.

562 Külköylüoğlu O, Sari N, Akdemir D, Yavuzatmaca M, Altinbağ C. 2012 Distribution of sexual 563 and asexual ostracoda (Crustacea) from different altitudinal ranges in the Ordu region of Turkey:

564 Testing the Rapoport Rule. High Alt. Med. Biol. 13, 126-137.

565 Lavanchy G, Strehler M, Roman MNL, Lessard-Therrien M, Humbert JY, Dumas Z, Jalvingh K, 566 Ghali K, Fontcuberta García-Cuenca A, Zijlstra B, Arlettaz R, Schwander T. 2016 Habitat 567 heterogeneity favours asexual reproduction in natural populations of grassthrips. Evolution 70, 568 1780-1790.

569 Lehto MP, Haag CR. 2010 Ecological differentiation between coexisting sexual and asexual 570 strains of Daphnia pulex. J. Anim. Ecol. 79, 1241-1250. 
571 Lehtonen J, Jennions MD, Kokko H. 2012 The many costs of sex. Trends Ecol. Evol. 27, 172572178.

573 Lively CM. 1987 Evidence from a New Zealand snail for the maintenance of sex by parasitism.

574 Nature 328, 519-521.

575 Lively CM. 1992 Parthenogenesis in a freshwater snail: reproductive assurance versus parasitic 576 release. Evolution 46, 907-913.

577 Lively CM, Morran LT. 2014 The ecology of sexual reproduction. J. Evol. Biol. 27, 1292-1303.

578 Lo EY, Stefanović S, Dickinson TA. 2009. Population genetic structure of diploid sexual and 579 polyploid apomictic hawthorns (Crataegus; Rosaceae) in the Pacific Northwest. Mol. Ecol. 18, $580 \quad 1145-1160$.

581 Lovell JT, Williamson RJ, Wright SI, McKay JK, Sharbel TF. 2017 Mutation accumulation in an 582 asexual relative of Arabidopsis. PLoS Genet. 13, e1006550.

583 Lumley AJ, Michalczyk Ł, Kitson JJN, Spurgin LG, Morrison CA, Godwin JL, Dickinson ME, 584 Martin OY, Emerson BC, Chapman T, Gage MJJ. 2015 Sexual selection protects against 585 extinction. Nature 522, 470-473.

586 Mark Welch DB, Meselson MS. 2001 Rates of nucleotide substitution in sexual and anciently 587 asexual rotifers. Proc. Nat. Acad. Sci. USA 98, 6720-6724.

588 Mau M, Lovell JT, Corral JM, Kiefer C, Koch M, Aliyu OM, Sharbel TF. 2015 Hybrid apomicts 589 trapped in the ecological niches of their sexual ancestors. Proc. Nat. Acad. Sci. USA 112, E2357590 E2365.

591 Maynard Smith J. 1971 What use is sex? J. Theor. Biol. 30, 319-335.

592 Maynard Smith J. 1978 The evolution of sex. London, UK: Cambridge University Press.

593 McDonald MJ, Rice DP, Desai MM. 2016 Sex speeds adaptation by altering the dynamics of 594 molecular evolution. Nature 531, 233-236.

595 McKone MJ, Gibson AK, Cook D, Freymiller LA, Mishkind D, Quinlan A, York JM, Lively 596 CM, Neiman M. 2016 Fine-scale association between parasites and sex in Potamopyrgus 597 antipodarum within a New Zealand lake. NZ J. Zool. 40, 330-333.

598 Menken S, Smits E, Den Nijs JCM. 1995 Genetical population structure in plants: gene flow 599 between diploid sexual and triploid asexual dandelions (Taraxacum section Ruderalia).

600 Evolution 49, 1108-1118. 
Meirmans PG. 2005 Ecological and genetic interactions between diploid sexual and triploid apomictic dandelions. Ph.D. Thesis. Instituut voor Biodiversiteit en Ecosysteem Dynamica,

603 Universiteit van Amsterdam.

Meirmans PG, Calame FG, Bretagnolle F, Felber F, den Nijs JCM. 1999 Anthropogenic disturbance and habitat differentiation between sexual diploid and apomictic triploid Taraxacum sect. Ruderalia. Folia Geobot. 34, 451-469.

607 Meirmans S, Strand R. 2010. Why are there so many theories for sex, and what do we do with 608 them? J. Hered, 101, S3-S12.

609 Meirmans S, Meirmans PG, Kirkendall LR. 2012 The costs of sex: Facing real-world 610 complexities. Q. Rev. Biol. 87, 19-40.

611 Moritz C, McCallum H, Donnellan S, Roberts JD. 1991 Parasite loads in parthenogenetic and 612 sexual lizards (Heteronotia binoei): support for the Red Queen hypothesis. Proc. Roy. Soc. Lond. 613 B Biol. Sci. 244, 145-149.

614 Muller HJ. 1964 The relation of recombination of mutational advance. Mutat. Res. 106, 2-9.

615 Neiman M, Koskella B. 2009. Sex and the Red Queen. In Lost Sex (eds Schön I, Martens K, van 616 Dijk P), pp. 133-159. Amsterdam: Springer.

617 Neiman M, Schwander T. 2011 Using parthenogenetic lineages to identify advantages of sex. 618 Evol. Biol. 38, 115-123.

619 Neiman M, Jokela J, Lively CM. 2005 Variation in asexual lineage age in Potamopyrgus 620 antipodarum, a New Zealand snail. Evolution 59, 1945-1952.

621 Neiman M, Lively CM, Meirmans S. 2017 Why sex? A pluralist approach revisited. Trends 622 Ecol. Evol. 32, 589-600.

623 Neiman M, Hehman G, Miller JT, Logsdon JM Jr, Taylor DR. 2010 Accelerated mutation 624 accumulation in asexual lineages of a freshwater snail. Mol. Biol. Evol. 27, 954-963.

625 Normark BB, Moran NA. 2000. Testing for the accumulation of deleterious mutations in asexual 626 eukaryote genomes using molecular sequences. J. Nat. Hist. 34, 1719-1729.

627 O'Connell LM, Eckert CG. 2001 Differentiation in reproductive strategy between sexual and 628 asexual populations of Antennaria parlinii (Asteraceae). Evol. Ecol. Res. 3, 311-330.

629 Paczesniak D, Adolfsson S, Liljeroos K, Klappert K, Lively CM, Jokela J. 2014 Faster clonal 630 turnover in high-infection habitats provides evidence for parasite-mediated selection. J. Evol.

631 Biol. 27, 417-428. 
632 Paland S, Lynch M. 2006 Transitions to asexuality result in excess amino acid substitutions.

633 Science 311, 990-992.

634 Pellino M, Hojsgaard D, Schmutzer T, Scholz U, Hörandl E, Vogel H, Sharbel TF. 2013 Asexual

635 genome evolution in the apomictic Ranunculus auricomus complex: examining the effects of

636 hybridization and mutation accumulation. Mol. Ecol. 22, 5908-5921.

637 Peters AD, Lively CM. 1999 The red queen and fluctuating epistasis: a population genetic

638 analysis of antagonistic coevolution. Am. Nat. 154, 393-405.

639 Pound GE, Doncaster CP, Cox SJ. 2002 A Lotka-Volterra model of coexistence between a

640 sexual population and multiple asexual clones. J. Theor. Biol. 217, 535-545.

641 Rho M, Schaack S, Gao X, Kim S, Lynch M, Tang H. 2010 LTR retroelements in the genome of 642 Daphnia pulex. BMC Genomics 11, 425.

643 Ross L, Hardy NB, Okusu A, Normark BB. 2013 Large population size predicts the distribution 644 of asexuality in scale insects. Evolution 67, 196-206.

645 Schmit O, Adolfsson S, Vandekerkhove J, Rueda J, Bode SNS, Rossetti G, Michalakis Y, Jokela 646 J, Martens K, Mesquita-Joanes F. 2013a The distribution of sexual reproduction of the 647 geographic parthenogen Eucypris virens (Crustacea: Ostracoda) matches environmental 648 gradients in a temporary lake. Can. J. Zool. 91, 660-671.

649 Schmit O, Bode SNS, Camacho A, Horne DJ, Lamatsch DK, Martens K, Martins MJF, 650 Namiotko T, Rossetti G, Rueda-Sevilla J, Schön I, Vandekerkhove J, Mesquita-Joanes F. 2013b 651 Linking present environment and the segregation of reproductive modes (geographical 652 parthenogenesis) in Eucypris virens (Crustacea: Ostracoda). J. Biogeog. 40, 2394-2408.

653 Sharp N, Otto SP. 2016 Evolution of sex: Using experimental genomics to select among 654 competing theories. Bioessays 38, 751-757.

655 Singh ND, Criscoe DR, Skolfield S, Kohl KP, Keebaugh ES, Schlenke TA. 2015 Fruit flies 656 diversify their offspring in response to parasite infection. Science 349, 747-750.

657 Song Y, Drossel B, Scheu S. 2011 Tangled Bank dismissed too early. Oikos 120, 1601-1607.

658 Stefani, R. 1956. Il problema della partenogenesi in "Haploembia solieri" Ramb. (Embioptera659 Oligotomidae). Memorie dell'Accademia Lincei Rome Sez IIIa 5, 127-201.

660 Stefani, R. 1959. Aspetti zoogeografici di un problema evolutivo. Bollettino di Zoologia Torino 661 26, 105-114.

662 Steiner BL, Armbruster GFJ, Scheepens JF, Stöcklin J. 2012 Distribution of bulbil- and seed663 producing plants of Poa alpine (Poaceae) and their growth and reproduction in common gardens 664 suggest adaptation to different elevations. Am. J. Bot. 99, 2035-2044. 
665 Sterken MG, Snoek LB, Kammenga JE, Andersen EC. 2015 The laboratory domestication of 666 Caenorhabditis elegans. Trends Genet. 31, 224-231.

667 Tarkhnishvili D, Gavashelishvili A, Avaliani A, Murtskhvaladze M, Mumladze L. 2010

668 Unisexual rock lizard might be outcompeting its bisexual progenitors in the Caucasus. Biol. J.

669 Linn. Soc. 101, 447-460.

670 Tilquin A, Kokko H. 2016. What does the geography of parthenogenesis teach us about sex?

671 Phil. Trans. Roy. Soc. Lond. B 371, 20150538.

672 Tucker A, Ackerman M, Eads B, Xu S, Lynch M. 2013 Population-genomic insights into the 673 evolutionary origin and fate of obligately asexual Daphnia pulex. Proc. Nat. Acad. Sci. USA 110, 674 15740-15745.

675 van der Kooi CJ, Matthey-Doret C, Schwander T. 2017 Evolution and comparative ecology of 676 parthenogenesis. Evol. Lett., in press, DOI: 10.1002/ev13.30.

677 Verduijn MH, Van Dijk PJ, Van Damme JMM. 2004 The role of tetraploids in the sexual678 asexual cycle in dandelions (Taraxacum). Heredity 93, 390-398.

679 Vergara D, Lively CM, King KC, Jokela J. 2013 The geographic mosaic of sex and infection in 680 lake populations of a New Zealand snail at multiple spatial scales. Am. Nat. 182, 484-493.

681 Vergara D, Jokela J, Lively CM. 2014 Infection dynamics in coexisting sexual and asexual host 682 populations: support for the Red Queen hypothesis. Am. Nat. 184, S22-S30.

683 Verhoeven KJF, Biere A. 2013 Geographic parthenogenesis and plant-enemy interactions in the 684 common dandelion. BMC Evol. Biol. 13, 23.

685 Vrijenhoek RC. 1979 Factors affecting clonal diversity and coexistence. Am. Zool. 19, 787-797.

686 West SA, Lively CM, Read AF. 1999 A pluralist approach to sex and recombination. J. Evol.

687 Biol. 12, 1003-1012.

688 Williams GC. 1975 Sex and evolution. Princeton, USA: Princeton University Press.

689 Xu S, Omilian AR, Cristescu ME. 2011 High rate of large-scale hemizygous deletions in 690 asexually propagating Daphnia: Implications for the evolution of sex. Mol. Biol. Evol. 28, 335691342. 


\section{Table Caption}

698 Table 1. Summary of the results of our literature survey. We list the number of studies that

699 provided support (green) or no support (red) for the different categories of mechanisms for sex,

700 separated by taxonomic group. In total, 66 studies and 83 cases were included; studies that tested

701 multiple mechanisms or included multiple taxonomic groups were counted as "cases" multiple

702 times. Numbers in brackets after the name of the taxonomic group indicate the number of studies

703 for each group.

$\begin{array}{lcccccc}\text { Class/clade } & \text { Parasites } & \begin{array}{c}\text { Rate of } \\ \text { adaptive } \\ \text { evolution }\end{array} & \begin{array}{c}\text { Harmful } \\ \text { Mutations }\end{array} & \begin{array}{c}\text { Niche } \\ \text { differentiation }\end{array} & \begin{array}{c}\text { Niche } \\ \text { breadth }\end{array} & \text { Other } \\ \text { Reptiles (8) } & 2 / 1 & - & - & 2 / 2 & 0 / 2 & - \\ \text { Insects (6) } & 0 / 2 & - & 2 / 1 & - & 0 / 2 & - \\ \text { Branchiopods (8) } & 0 / 1 & - & 4 / 0 & 2 / 0 & 0 / 1 & 1 / 0 \\ \text { Ostracods (4) } & 0 / 1 & 2 / 0 & - & 2 / 1 & 0 / 2 & - \\ \text { Arachnids (1) } & - & - & 0 / 1 & - & - & - \\ \text { Arthropods; general (1) } & - & - & 0 / 1 & - & - & - \\ \text { Gastropods (23) } & 17 / 4 & 0 / 1 & 4 / 0 & 1 / 0 & -1 / 0 & - \\ \text { Rotifers (2) } & - & - & 1 / 1 & - & - & - \\ \text { Anopla (1) } & - & - & 1 / 0 & - & - & - \\ \text { Magnoliopsida (11) } & 2 / 0 & - & 2 / 1 & 5 / 1 & - & - \\ \text { Fungi (1) } & - & - & - & 1 / 0 & 1 / 7 & 5 / 1 \\ \text { TOTAL } & 21 / 9 & 2 / 1 & 14 / 5 & 13 / 4 & & \end{array}$

